\title{
Treatment of posttraumatic syringomyelia: evidence from a systematic review
}

\author{
Andrea Kleindienst ${ }^{1,2}$ (D) Francisco Marin Laut ${ }^{3} \cdot$ Verena Roeckelein $^{2} \cdot$ Michael Buchfelder $^{2} \cdot$ Frank Dodoo-Schittko $^{4}$
}

Received: 27 May 2020 / Accepted: 4 August 2020 / Published online: 20 August 2020

(C) The Author(s) 2020

\begin{abstract}
Background Following spinal cord injury (SCI), the routine use of magnetic resonance imaging (MRI) resulted in an incremental diagnosis of posttraumatic syringomyelia (PTS). However, facing four decades of preferred surgical treatment of PTS, no clear consensus on the recommended treatment exists. We review the literature on PTS regarding therapeutic strategies, outcomes, and complications.

Methods We performed a systematic bibliographic search on ("spinal cord injuries" [Mesh] AND "syringomyelia" [Mesh]). English language literature published between 1980 and 2020 was gathered, and case reports and articles examining syrinx due to other causes were excluded. The type of study, interval injury to symptoms, severity and level of injury, therapeutic procedure, duration of follow-up, complications, and outcome were recorded.

Results Forty-three observational studies including 1803 individuals met the eligibility criteria. The time interval from SCI to the diagnosis of PTS varied between 42 and 264 months. Eighty-nine percent of patients were treated surgically $(n=1605)$ with a complication rate of $26 \%$. Symptoms improved in $43 \%$ of patients postoperatively and in $2 \%$ treated conservatively. Stable disease was documented in $50 \%$ of patients postoperatively and in $88 \%$ treated conservatively. The percentage of deterioration was similar (surgery 16\%, $0.8 \%$ dead; conservative 10\%). Detailed analysis of surgical outcome with regard to symptoms revealed that pain, motor, and sensory function could be improved in 43 to $55 \%$ of patients while motor function deteriorated in around $25 \%$. The preferred methods of surgery were arachnoid lysis $(48 \%)$ and syrinx drainage $(31 \%)$.

Conclusion Even diagnosing PTS early in its evolution with MRI, to date, no satisfactory standard treatment exists, and the present literature review shows similar outcomes, regardless of the treatment modality. Therefore, PTS remains a neurosurgical challenge. Additional research is required using appropriate study designs for improving treatment options.
\end{abstract}

Keywords Syringomyelia $\cdot$ Trauma $\cdot$ Hydromyelia $\cdot$ Treatment $\cdot$ Etiology $\cdot$ Spinal cord injury

This article is part of the Topical Collection on Spine - Other

Andrea Kleindienst

andrea.kleindienst@uk-erlangen.de

Francisco Marin Laut

miguel.laut@uca.es

Verena Roeckelein

v.n.roeckelein@googlemail.com

Michael Buchfelder

michael.buchfelder@uk-erlangen.de

Frank Dodoo-Schittko

frank.dodoo-schittko@med.ovgu.de
1 Department of Neurosurgery, Friedrich-Alexander-University Erlangen-Nurnberg, Erlangen, Germany

2 Department of Spine Surgery, Krankenhaus Rummelsberg, Schwarzenbruck, Germany

3 Department of Neurosurgery, University Hospital Puerta de Mar, Cadiz, Spain

4 Institute of Social Medicine and Health Systems Research, Otto von Guericke University Magdeburg, Magdeburg, Germany 


\section{Abbreviations \\ PTS Posttraumatic syringomyelia \\ SCI Spinal cord injury \\ MRI Magnetic resonance imaging \\ CT Computed tomography \\ CSF Cerebrospinal fluid}

ASIA American Spinal Injury Association

\section{Introduction}

Over the past decades, due to the more frequent routine use of magnetic resonance imaging (MRI) in the diagnostic process and follow-up for back pain and spine injuries, even distinctive features are increasingly detected. The attribution of a T2hyperintense medullary signal as a prominent central canal, hydro- and syringomyelia has been classified by Milhorat [ 40 , 41]. However, diagnostic criteria and terminology are used inconsistently. Batnitzky [6] differentiated primary congenital and secondary acquired forms of syringomyelia due to trauma, infection, tumor, or vascular disturbances. The pathophysiological mechanism of congenital syringomyelia is explained by the absence of a perforation of the rhombic roof and formation of the foramen Magendie during fetal weeks 6 to 8 [21], resulting in a persistent patent central canal. Conversely, acquired syringomyelia has been linked to intermittent sharp increases in cerebrospinal fluid (CSF) pressure associated with venous pressure fluctuations as the underlying distending force [61]. An experimental modeling of a phase difference between the pressure pulse in the spinal subarachnoid space and the perivascular spaces suggests that mechanical perturbations caused by arachnoiditis exacerbate the phase-lag effect [15]. As soon as the intrinsic fluid storage capacity of the spinal cord is overloaded, medullary edema may develop, presenting as a hyperintense T2-weighted signal and referred to as the "pre-syrinx" state [20].

Following spinal cord injury (SCI), local ischemia, liquefaction of hematoma, and/or autolytic processes, as well as subarachnoid scars limit the CSF flow [17], thereby rendering the development of possible posttraumatic syringomyelia (PTS). In PTS, delayed progressive myelopathy develops often corresponding to spinal segments distant from the level of the original lesion. Besides CSF flow disturbances, posttraumatic kyphosis and the resulting spinal canal stenosis may promote the progression of PTS [1, 44].

Concerning preferred therapeutic strategies, in 2010, a consensus panel gave a strong recommendation for surgical intervention in the setting of motor neurological deterioration and a weak recommendation for spinal cord untethering with expansive duraplasty as the preferred first-line surgical technique [7]. Furthermore, they recommended no decompression at the time of initial injury to limit the future risk of syringomyelia, or for patients developing pain, sensory loss or for asymptomatic but expanding syrinx [7]. While for cervical spondylotic myelopathy, two randomized controlled trials (RCT) compare different surgical techniques $[19,22]$, no RCT, or, at least, a prospective observational study compares a non-operative to surgical treatment-neither in cervical myelopathy nor in PTS. Here, we present the results of a systematic literature search on PTS for treatment strategy, outcome, and complications.

\section{Methods}

Eligibility All studies describing the treatment or reporting the effects of treatment of PTS from 1980 to 2020 were included in this review. Case reports including less than three individuals and animal studies were not included. Apart from this, no restrictions were placed on the study type (experimental or observational studies), or sample size.

Literature search and data extraction The retrieval of studies was performed in PubMed using the combined filter and Medical Subject Headings (MeSH) term: ("spinal cord injuries" [Mesh] AND "syringomyelia" [Mesh]). Additionally, the Cochrane Central Register of Controlled Trials (CENTRAL), the Cochrane Database of Systematic Reviews, Web of Science, Scopus, and Google Scholar were searched for eligible studies. All records were screened based on title and abstract independently by two authors (FDS and AK) separately. In cases of discordance, the records were included in the full-text screening. Finally, the remaining records were evaluated by reading the full-text papers. All relevant characteristics (study type, sample size, level and severity of the injury, interval injury to symptoms, surgical technique, follow-up period, main findings) reported in the manuscripts were extracted into evidence tables. Due to a high level of heterogeneity of the studies and many insufficient study designs, no pooled effect estimates were calculated. Instead, a descriptive summary was carried out.

Risk of bias assessment Since the Newcastle-Ottawa Scale (NOS) is only suitable for assessing the quality of casecontrol and prospective cohort studies, we used a risk-ofbias measurement instrument based on the NOS but also suitable for studies which cannot be subsumed under these gold standard observational study designs. A detailed description of this tool has been published by Dodoo-Schittko et al. [12]. All included studies were evaluated by two authors (AK and FDS). Subsequently, disparate ratings were discussed until consensus was reached. 


\section{Results}

\section{Systematic literature search}

The electronic search revealed 599 scientific reports, and the PRISMA flow diagram of the screening process is presented in Fig. 1. After screening the title and abstract, 61 articles were included in the full-text screening process. One study was excluded because of overlapping data [54], and one because the full text was not available in English [10]. Finally, a total of 43 studies met the eligibility criteria. The extracted information of these studies is shown in Table 1. All cohorts/ samples were independent, and we could not identify any overlap of included individuals. Overall, the sample sizes of the clinical studies detected by literature search ranged from case series of three up to studies including 600 individuals [2, $4,5,9,11,13,14,16,18,23-40,42-53,55,56,59,60,62]$. Observational designs were applied in all studies. One study used an experimental design investigating the effect of shunt insertion on syrinx length and size in an animal model [8] and an observational study in dogs [3]. Both were excluded because they were not including human subjects.

\section{Patients characteristics}

The studies collect data from 1803 patients. The time interval from the spinal injury to the onset of symptoms varies between
42 and 264 months. Pain, motor, and sensory function compromise are the most frequent symptoms, while autonomic dysfunction is uncommon. Complete SCI preponderates (mean 63\%) over incomplete (mean 37\%). The most frequent locations of spinal injuries were the thoracic region (mean $48 \%$ ) and the cervical region (mean 41\%). The lumbar region (mean 10\%) and medulla oblongata (mean $<1 \%$ ) were hardly affected.

\section{Clinical outcome}

The mean follow-up period was 56 months in the observational studies. While $89 \%$ of patients were treated surgically, of the remaining $11 \%$ treated conservatively, only those of Ronen et al. [45] received a rehabilitation $(n=5)$. The summarized results of the surgical and conservative treatment are presented in Table 2. Following surgery for PTS, $43 \%$ of patients improved clinically, and the MRI findings in $75 \%$ of patients; $50 \%$ remained stable, $16 \%$ deteriorated, and $0.8 \%$ died peri-procedural. Sufficient information about complications of the performed surgical procedures is not available in all studies. Six studies do not describe complications, and in another six studies, no complications were observed. Out of the 403 complications following surgery (26\%), a drain or valve dysfunction was most often reported (21\%). A CSF leak was reported in $2.9 \%$, a transient neurological deficit in $2.8 \%$, a permanent neurological deficit in $2.5 \%$, and wound complications were reported in $2 \%$ of patients. Other
Fig. 1 PRISMA flow diagram of the screening process

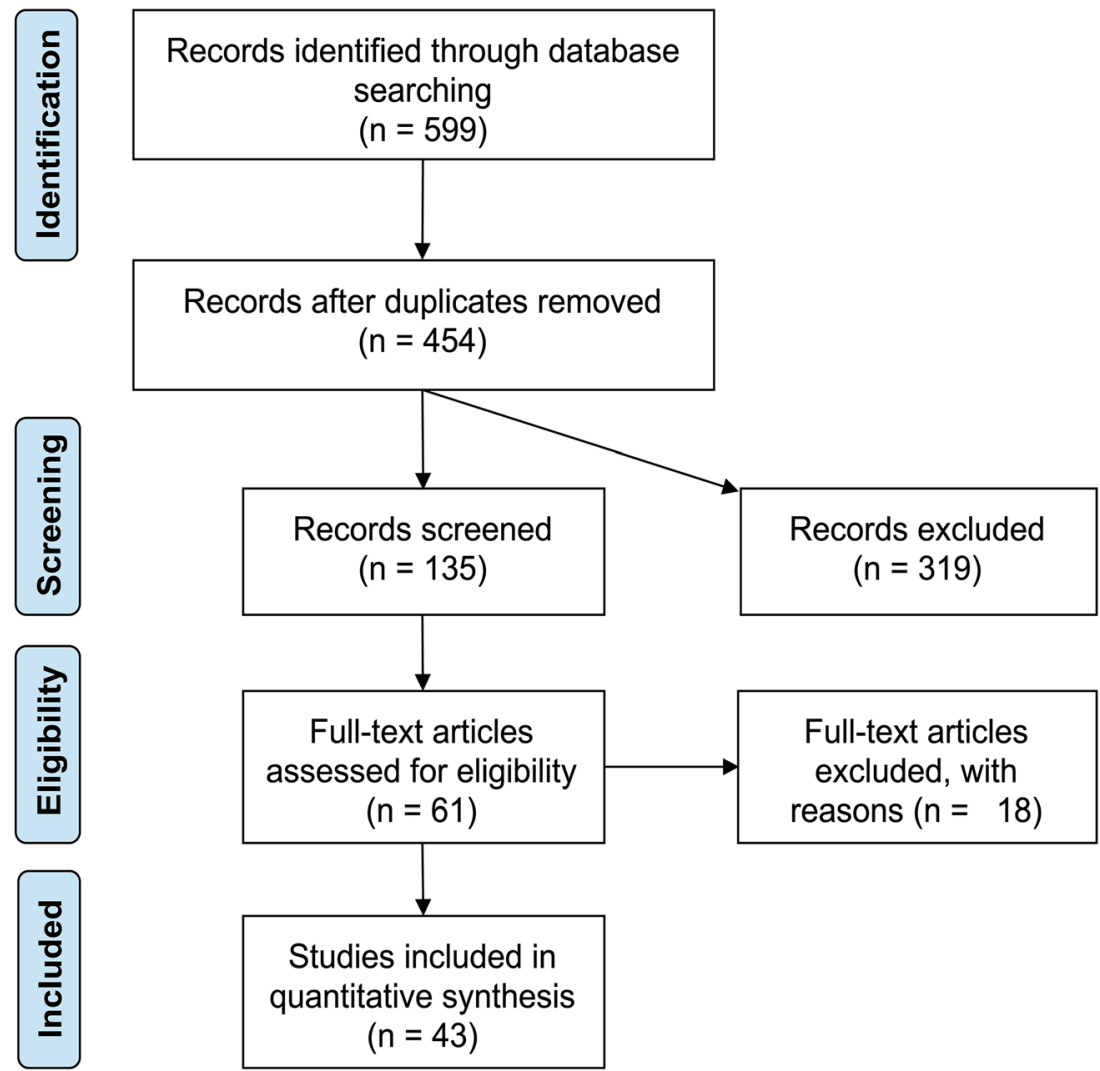




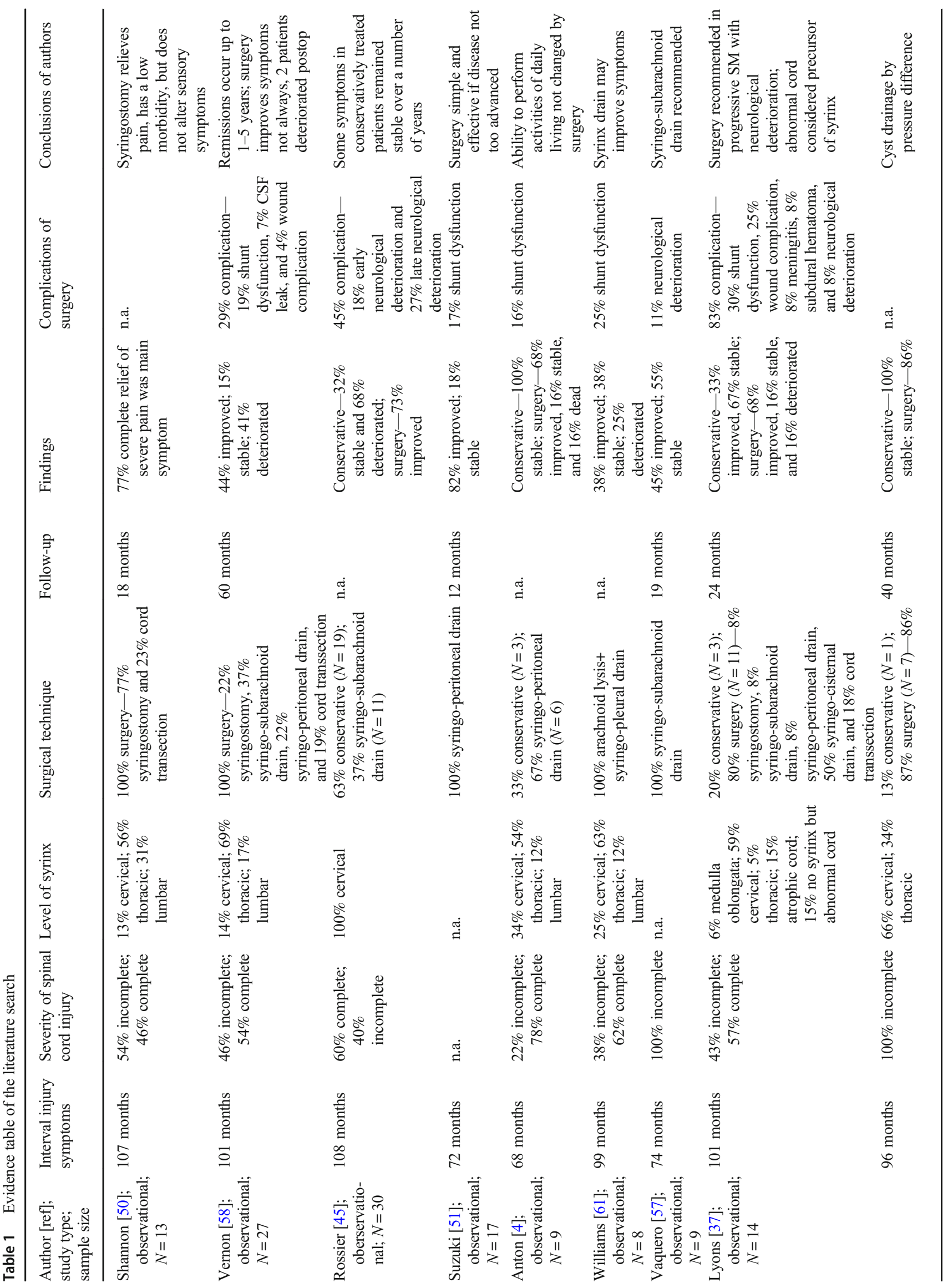




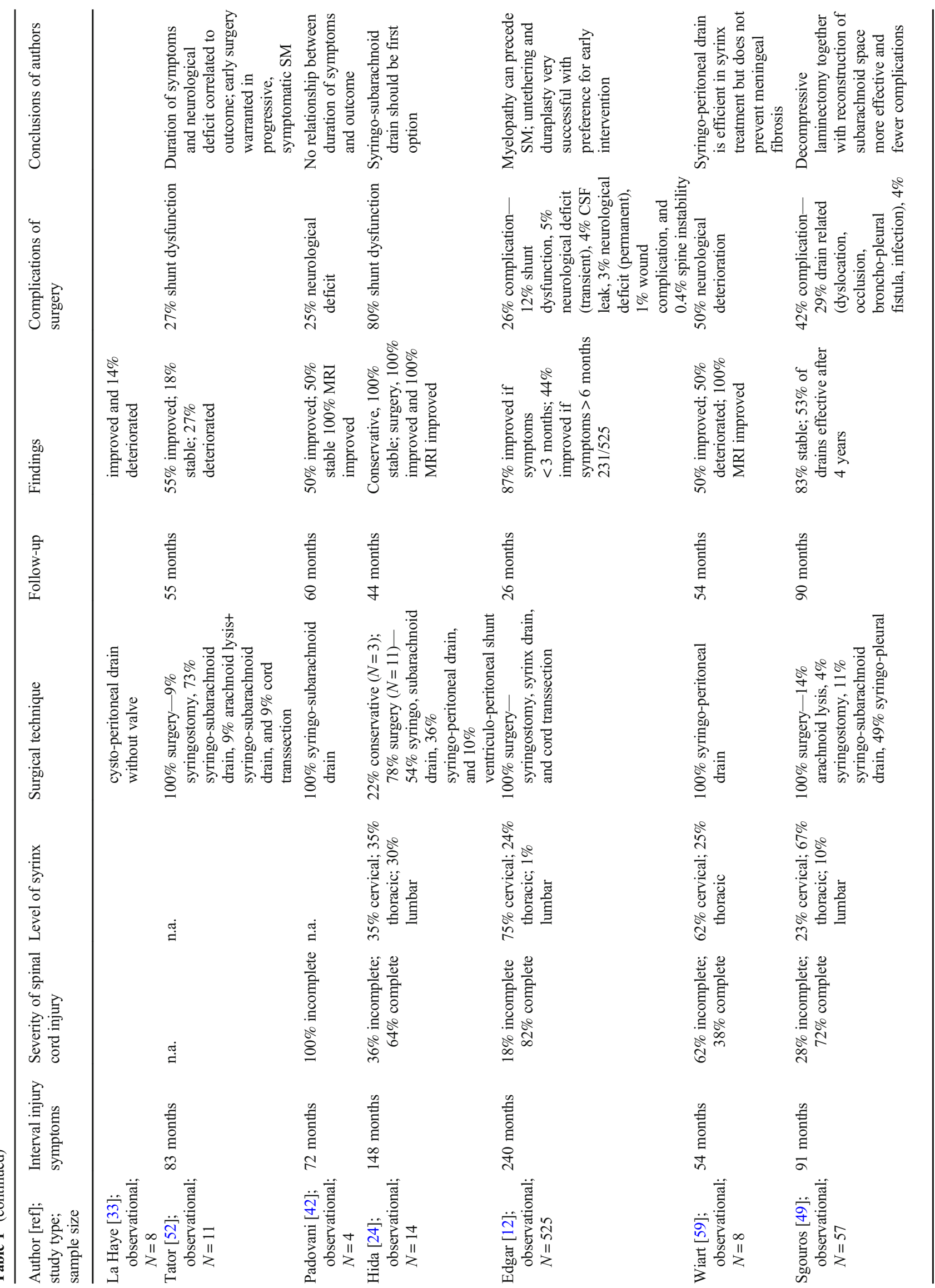




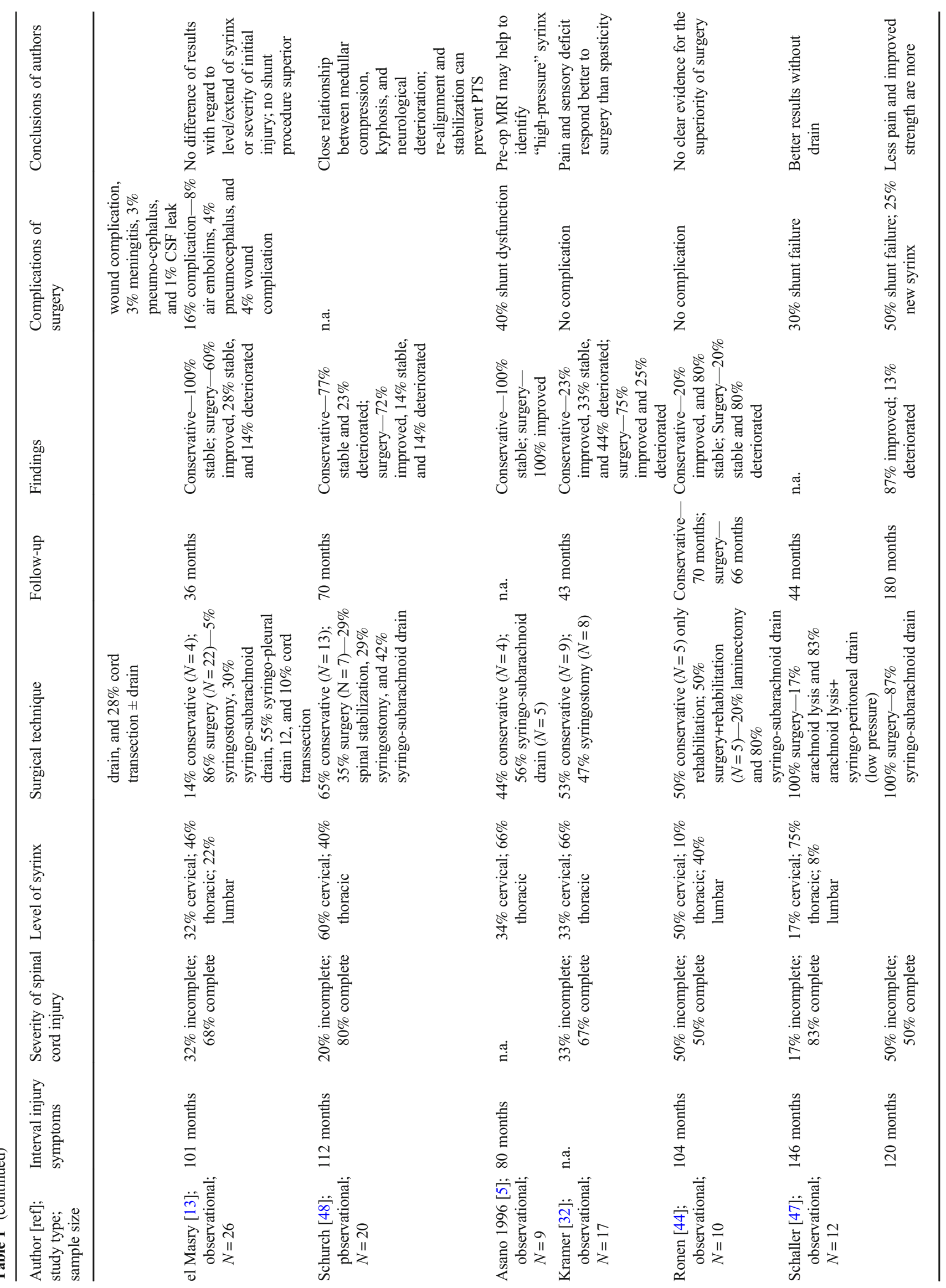




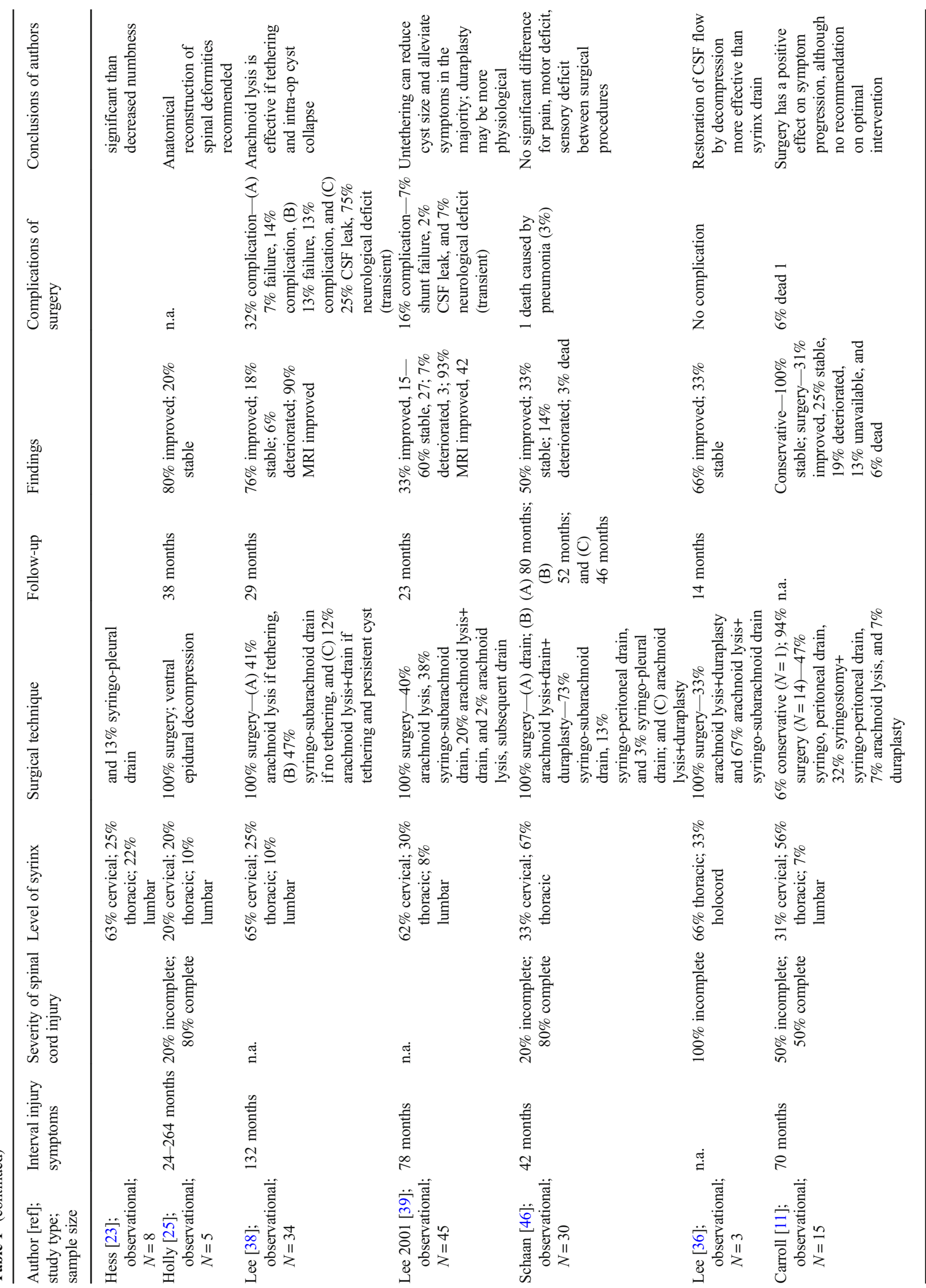




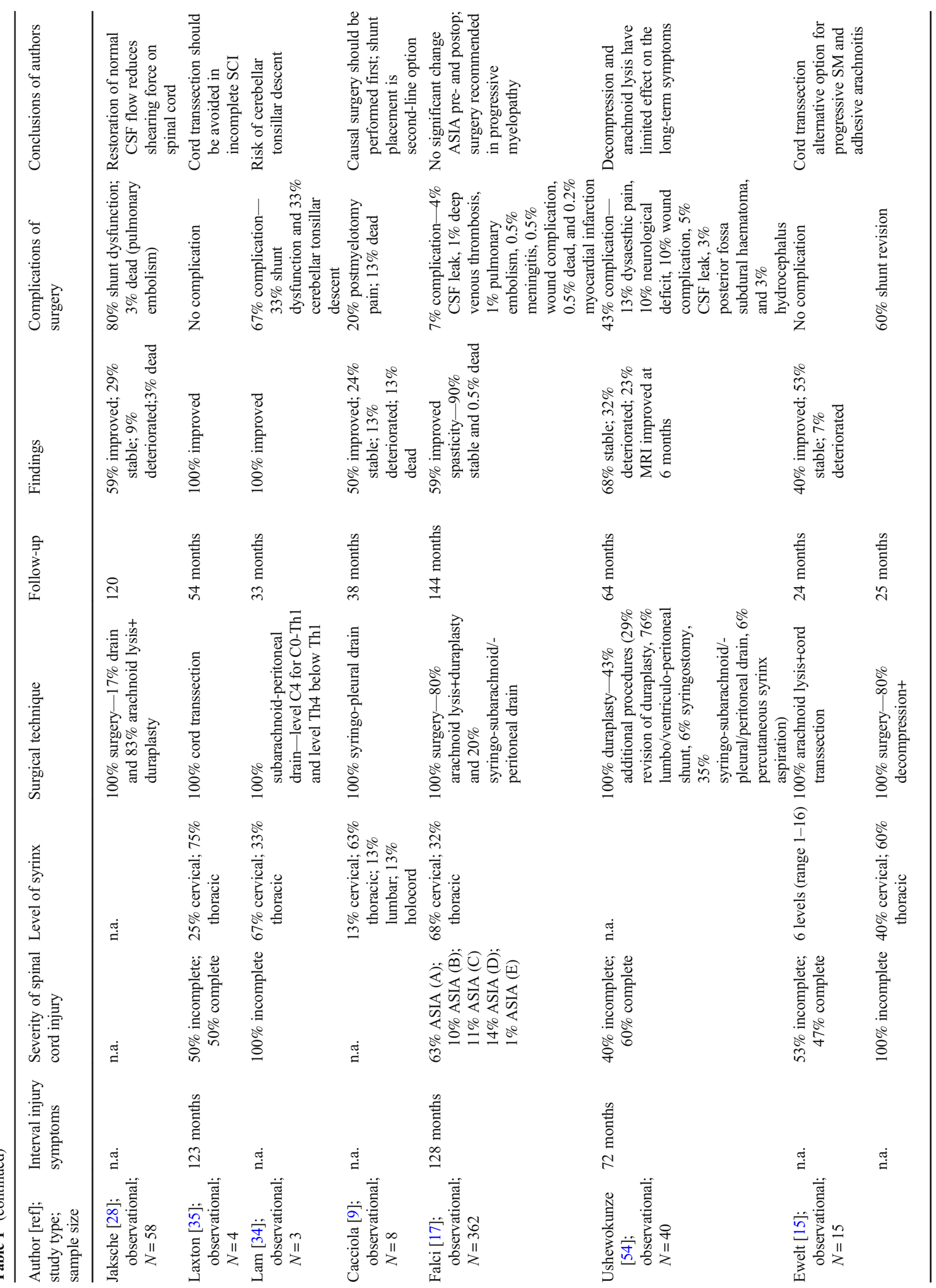




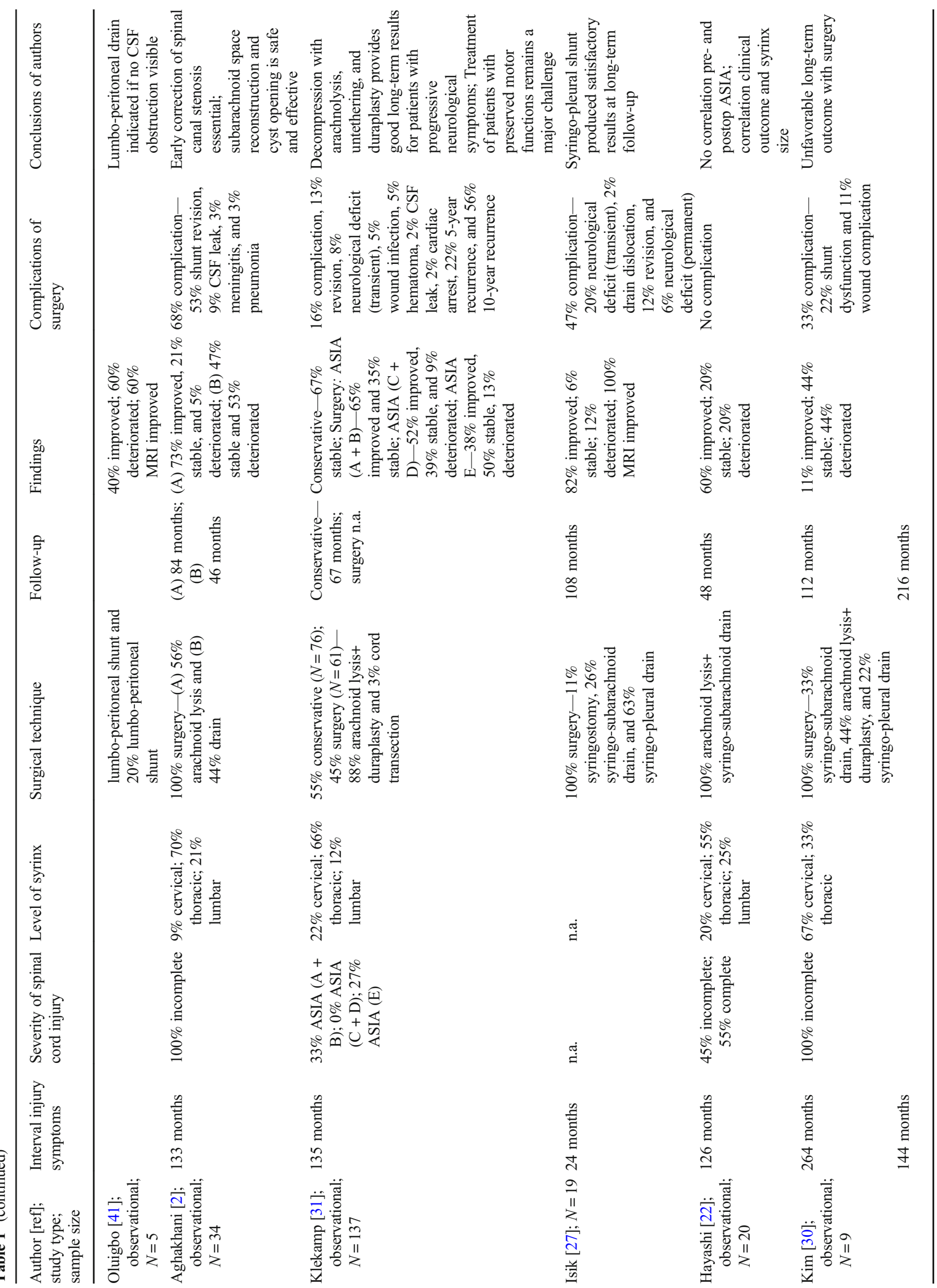




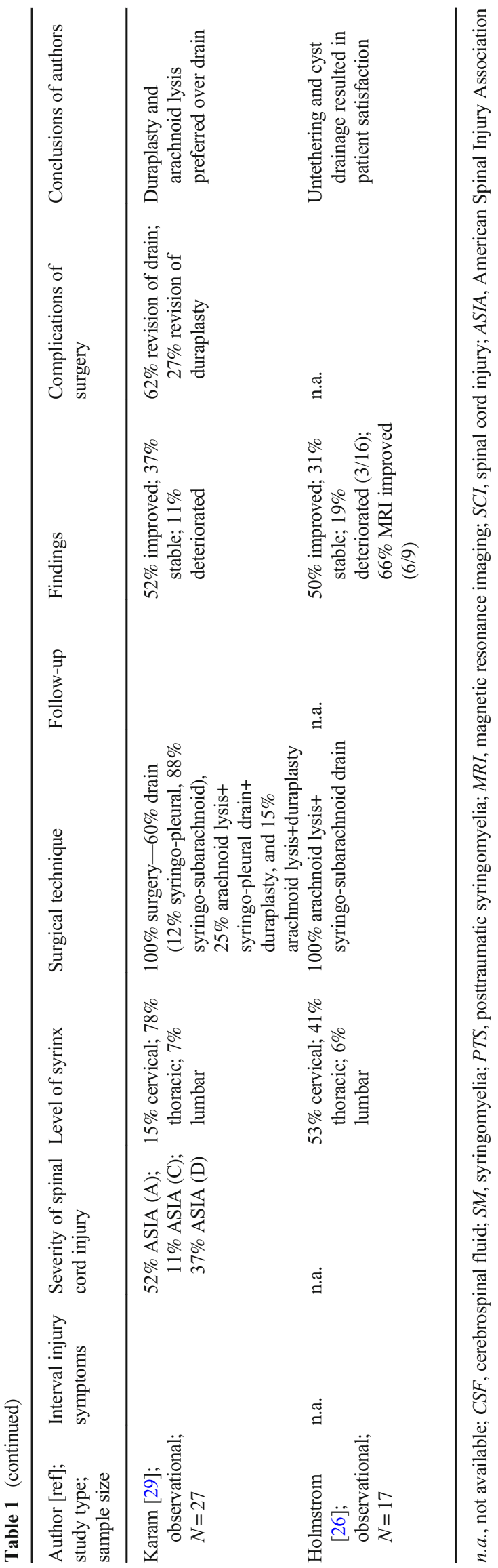

complications included venous thromboembolic event $(N=$ $7)$, meningitis $(N=6)$, pneumocephalus $(N=3)$, air embolism $(N=2)$, cerebellar tonsillar descent $(N=1)$, and cardiac arrest $(N=1)$.

A detailed analysis of surgical results concerning pain, sensory, motor, and autonomic function was performed by Vernon et al. in 27 patients [59], Lee et al. in 87 patients [37, 38], and Schaan et al. in 30 patients [47]. The results are presented in Table 3. Pain is improved in $43 \%$ of patients, sensory function in $49 \%$, and motor function in $55 \%$. On the other hand, pain is deteriorated in $15 \%$, sensory function in $27 \%$, motor function in $25 \%$, and autonomic function in almost all cases.

The type of surgical procedure on PTS was specified in 866 patients and is presented in Table 4. Arachnoid lysis was the procedure that was performed most often $(N=$ $418 ; 48 \%$ ), followed by various techniques of drain placement $(N=267 ; 31 \%)$. Procedures that were performed less frequently were cord transection $(N=51 ; 5.9 \%)$, syringostomy $(N=49 ; 5.7 \%)$, duraplasty $(N=41 ; 4.7 \%)$, a combination of arachnoid lysis and drain $(N=30$; $3.5 \%)$, decompression alone $(N=5 ; 0.6 \%)$, or shunt alone $(N=5 ; 0.6 \%)$.

Four studies directly compared the results of different treatment regimes in separate cohorts. The allocation process was either based on clinical findings [37, 38] or not described [2, 47], and the time point of outcome assessment is not always specified. In two separate studies, Lee et al. performed arachnoid lysis $(N=33)$, drain placement $(N=33)$, and a combination of both $(N=13)$. While the failure of drain placement $(N=5 ; 15 \%)$ is higher than of arachnoid lysis $(N=2 ; 6 \%)$, the incidence of procedure-related neurological deficits $(9 \%$ : arachnoid lysis $N=3$; drain $N=3$ ) and the overall improvement is comparable (pain 30\%: each $N=11$; sensory $21 \%$ : each $N=7$; motor 30-33\% arachnoid lysis $N=10$, drain $N=11)$. The results reported by Aghakhani et al. postoperatively were worse for drain placement $(N=15$; improvement $0 \%$; deterioration $53 \%)$ than for arachnolysis $(N=19$ : improvement $16 \%$; deterioration 5\%) but improved over time [2]. A combination of both techniques was performed in a minority of patients and was associated with a considerable morbidity $(53-75 \%)[2,37,38]$. Schaan et al. compared drain placement $(N=18$ : improvement 33-38\%; deterioration 13$31 \%)$ and duraplasty $(N=12$; improvement $45-100 \%$; deterioration 0-18\%) [47].

The results of the less-often performed procedures are better, although based on small sample sizes: cord incision or transection resulted in an improvement of 50 to $100 \%(N=$ 8) [58], syringostomy resulted in an improvement of $47 \%$ to $71 \%(N=19)$ [58], and duraplasty resulted in an improvement of $33 \%$ to $100 \%(N=12)$ [47].

Without a surgical treatment - i.e., following a "conservative" treatment $-2 \%$ of patients improved and $88 \%$ remained 
Table 2 Results of surgical and conservative treatment in posttraumatic syringomyelia

\begin{tabular}{lll}
\hline Detailed results of treatment & Surgery $(N=1605)$ & Conservative $(N=198)$ \\
\hline MRI improved & $123 / 164(75 \%)$ & n.a. \\
Improved & $510 / 1175(43 \%)$ & $4(2 \%)$ \\
Stable & $585 / 1078(50 \%)$ & $174(88 \%)$ \\
Deteriorated & $108 / 659(16 \%)$ & $20(10 \%)$ \\
Dead & $8 / 1021(0.8 \%)$ & n.a. \\
Complications & $403 / 1561(26 \%)$ & n.a. \\
Drain or valve dysfunction & $207 / 973(21 \%)$ & \\
CSF leak & $46 / 1561(2.9 \%)$ & \\
Transient neurological deficit & $44 / 1561(2.8 \%)$ & \\
Permanent neurological deficit & $39 / 1561(2.5 \%)$ & \\
Wound complication & $32 / 1561(2.0 \%)$ & \\
Other & & \\
Venous thromboembolic events & 7 & \\
Meningitis & 6 & \\
Pneumencephalus & 3 & \\
Subdural hematoma & 2 & \\
Air embolism & 2 & \\
Cerebellar tonsillar descent & 1 & \\
Cardiac arrest & 1 & \\
\hline
\end{tabular}

It is important to note that the comparison of surgical and conservative treatment lacks a baseline, which carries the risk of selection bias per chosen treatment

MRI, magnetic resonance imaging; CSF, cerebrospinal fluid stable, while $10 \%$ of patients deteriorated (total $N=198$; Table 2) $[4,5,11,14,25,32-34,40,45,46,49]$.

One experimental study including six patients (male, 3050 years) into a phase 2 trial injecting autologous mesenchymal stromal cells into the syrinx of PTS patients was not included in the above-mentioned analysis because it is a novel therapeutic approach [57]. The time interval between SCI and treatment varied from 5.8 to 27.7 years, and irrespective of syrinx size, $300 \times 10^{6}$ autologous expanded mesenchymal stromal cells, supported in autologous plasma were administered into the syrinx. The patients were followed up for 6 months, and the authors report in all patients variable improvement in clinical scales, mainly in the scales related to sphincter dysfunction and neuropathic pain [57].

\section{Discussion}

Over the past four decades, PTS is diagnosed more frequently and surgical techniques became more elaborate. Consequently, in a review paper (2010), Bonfield et al. presented recommendations of a consensus panel for surgical intervention in the setting of motor neurological deterioration and for spinal cord untethering with duraplasty as the preferred surgical technique [7]. Interestingly, they recommended against the direct decompression at the time of initial injury as well as against surgical interventions for patients developing pain, sensory loss, or for asymptomatic but radiologically expanding syrinx [7]. By 2020, still, no prospective study is available comparing non-operative and surgical treatmentneither in cervical myelopathy nor in PTS.

Here, we present the results of a systematic bibliographic literature search on PTS for treatment strategy, outcome, and complications. The risk of bias assessment revealed a high or unclear risk of selection bias in all studies. In addition, the risk of information bias was present in many studies, notably in the assessment of patient-reported outcome measurements. This is because of the use of non-validated measurement instruments. The present literature review reveals that $89 \%$ of the included 1803 patients were treated surgically. This fact can be probably attributed to a publication bias. Nevertheless, 12 studies including 198 PTS patients treated conservatively have been published $[4,5,11,14,25,32-34,40,45,46$, 49]. In contrast with the expert recommendations of 2010 [7], we also appreciate the results of these conservatively treated PTS patients.

Effect of intervention on specific symptoms The 2010 recommendations for surgical intervention in PTS advocate spinal cord untethering with duraplasty in the setting of motor neurological deterioration but against surgery for pain and sensory deterioration [7]. When we analyzed the outcome of 
Table 3 Detailed analysis of surgical results concerning pain, sensory, motor, and autonomic function

\begin{tabular}{|c|c|c|c|c|}
\hline Results of treatment & Pain & $\begin{array}{l}\text { Sensory } \\
\text { function }\end{array}$ & $\begin{array}{l}\text { Motor } \\
\text { function }\end{array}$ & $\begin{array}{l}\text { Autonomic } \\
\text { dysfunction }\end{array}$ \\
\hline Improved total & $\begin{array}{l}46 / 106 \\
\quad(43 \%)\end{array}$ & $42 / 85(49 \%)$ & $50 / 91(55 \%)$ & $2 / 15(13 \%)$ \\
\hline \multicolumn{5}{|l|}{ Vernon [54] (total $N=27)$} \\
\hline Syringostomy $(N=3)$ & $3 / 3$ & $0 / 2$ & $1 / 3$ & $0 / 1$ \\
\hline Syringostomy + drain $(N=16)$ & $8 / 14$ & $7 / 13$ & $9 / 13$ & - \\
\hline Cord incision/transection $(N=8)$ & $4 / 6$ & $3 / 6$ & $4 / 4$ & $0 / 2$ \\
\hline \multicolumn{5}{|l|}{ Lee [35] (total $N=34$ ) } \\
\hline Arachnoid lysis $(N=14)$ & $4 / 12$ & $3 / 6$ & $4 / 7$ & $1 / 3$ \\
\hline $\begin{array}{l}\text { Syringo-subarachnoid drain } \\
\qquad(N=16)\end{array}$ & $5 / 13$ & $3 / 6$ & $5 / 10$ & $0 / 2$ \\
\hline Arachnoid lysis + drain $(N=4)$ & $1 / 4$ & $1 / 3$ & $2 / 3$ & - \\
\hline \multicolumn{5}{|l|}{ Lee [34] (total $N=53$ ) } \\
\hline Arachnoid lysis $(N=19)$ & $6 / 15$ & $4 / 9$ & $6 / 10$ & $1 / 4$ \\
\hline $\begin{array}{l}\text { Syringo-subarachnoid drain } \\
(N=17)\end{array}$ & $5 / 13$ & $4 / 7$ & $6 / 11$ & $0 / 2$ \\
\hline Arachnoid lysis + drain $(N=9)$ & $2 / 8$ & $2 / 6$ & $3 / 6$ & $0 / 1$ \\
\hline \multicolumn{5}{|l|}{ Schaan [42] (total $N=30)$} \\
\hline Drain procedures $(N=18)$ & $5 / 14$ & $5 / 15$ & $5 / 13$ & - \\
\hline Drain + duraplasty $(N=5)$ & $1 / 1$ & $4 / 5$ & $3 / 5$ & - \\
\hline Duraplasty $(N=7)$ & $3 / 3$ & $6 / 7$ & $2 / 6$ & - \\
\hline Stable total & $\begin{array}{l}11 / 41 \\
(27 \%)\end{array}$ & $10 / 48(21 \%)$ & $9 / 44(20 \%)$ & $0 / 3(0 \%)$ \\
\hline \multicolumn{5}{|l|}{ Vernon $1983[54]($ total $N=27)$} \\
\hline Syringostomy $(N=3)$ & $0 / 3$ & $0 / 2$ & $1 / 3$ & $0 / 1$ \\
\hline Syringostomie + drain $(N=16)$ & $4 / 14$ & $1 / 13$ & $0 / 13$ & - \\
\hline Cord incision/transection $(N=8)$ & $2 / 6$ & $0 / 6$ & $0 / 4$ & $0 / 2$ \\
\hline \multicolumn{5}{|l|}{ Schaan [42] (total $N=30)$} \\
\hline Drain procedures $(N=18)$ & $5 / 14$ & $8 / 15$ & $4 / 13$ & - \\
\hline Drain + duraplasty $(N=5)$ & $0 / 1$ & $0 / 5$ & $1 / 5$ & - \\
\hline Duraplasty $(N=7)$ & $0 / 3$ & $1 / 7$ & $3 / 6$ & - \\
\hline Deteriorated total & $6 / 41(15 \%)$ & $13 / 48(27 \%)$ & $11 / 44(25 \%)$ & $3 / 3(100 \%)$ \\
\hline \multicolumn{5}{|l|}{ Vernon [54] (total $N=27)$} \\
\hline Syringostomy $(N=3)$ & $0 / 3$ & $2 / 2$ & $1 / 3$ & $1 / 1$ \\
\hline Syringostomie + drain $(N=16)$ & $2 / 14$ & $5 / 13$ & $4 / 13$ & - \\
\hline Cord incision/transection $(N=8)$ & $0 / 6$ & $3 / 6$ & $0 / 4$ & $2 / 2$ \\
\hline \multicolumn{5}{|l|}{ Schaan [42] (total $N=30)$} \\
\hline Drain procedures $(N=18)$ & $4 / 14$ & $2 / 15$ & $4 / 13$ & - \\
\hline Drain + duraplasty $(N=5)$ & $0 / 1$ & $1 / 5$ & $1 / 5$ & - \\
\hline Duraplasty $(N=7)$ & $0 / 3$ & $0 / 7$ & $1 / 6$ & - \\
\hline
\end{tabular}

surgery for PTS concerning specific neurological functions (Table 3), motor and sensory dysfunction responded better than pain to an intervention (improved motor 55\%, sensory $49 \%$, pain $43 \%$ ) but were also at a higher risk for deterioration (motor $25 \%$, sensory $27 \%$, pain $15 \%$ ) while the autonomic function was at a high risk for deterioration [37, 38, 47, 59]. Hence, although it is common practice in neurosurgery to prioritize motor symptoms in decision making for surgery and in guidelines, the recommendation by Bonfield et al. do not necessarily reflect the common practice in the existing literature on PTS.

The decision as to if, when, and what type of treatment to offer to a patient with PTS has changed over the past four decades. During the 1980s and early 1990s, surgical intervention including syringostomy and syrinx drainage was the preferred treatment option [58, 60]. Drainage complications resulted in the preference for the reconstruction of the subarachnoid space [50] or even a conservative treatment $[5,14,33$, 
Table 4 Detailed analysis of results of different surgical techniques in the treatment of posttraumatic syringomyelia

\begin{tabular}{|c|c|c|c|c|}
\hline Methods of surgical treatment $(N=866)$ & Improved & Stable & Deter. & Complications \\
\hline \multicolumn{5}{|l|}{ Arachnoid lysis $(N=418(48 \%))$} \\
\hline \multirow[t]{3}{*}{ Lee $[35](N=14)$} & Pain 33\% (4/12) & & & Failure $7 \%(1 / 14)$ \\
\hline & Sensory $50 \%(3 / 6)$ & & & Neurol. deficit $14 \%(2 / 14)$ \\
\hline & Motor 57\% (4/7) & & & CSF leak $7 \%(1 / 14)$ \\
\hline \multirow[t]{3}{*}{ Lee $[34](N=19)$} & Pain $40 \%(6 / 15)$ & & & Failure 5\% (1/19) \\
\hline & Sensory $44 \%(4 / 9)$ & & & Neurol. deficit $11 \%(2 / 19)$ \\
\hline & Motor 60\% (6/10) & & & CSF leak 5\% (4/19) \\
\hline Aghakhani [2] $(N=19)$ & Postop 16\% (3/19) & $79 \%(15 / 19)$ & $5 \%(1 / 19)$ & \\
\hline \multicolumn{5}{|c|}{$\begin{array}{l}\text { Drain (syringo-subarachnoid/pleural/peritoneal) } \\
\qquad(N=267(31 \%))\end{array}$} \\
\hline \multirow[t]{3}{*}{ Lee $[35](N=16)$} & Pain $38 \%(5 / 13)$ & & & Failure $13 \%(2 / 16)$ \\
\hline & Sensory $50 \%(3 / 6)$ & & & Trans. neurol. deficit 13\% (2/16) \\
\hline & Motor 50\% (5/10) & & & \\
\hline \multirow[t]{3}{*}{ Lee $[34](N=17)$} & Pain $38 \%(5 / 13)$ & & & Failure $18 \%(3 / 17)$ \\
\hline & Sensory $57 \%(4 / 7)$ & & & Trans. neurol. deficit 5\% (1/17) \\
\hline & Motor 54\% (6/11) & & & \\
\hline \multirow[t]{3}{*}{ Schaan $[42](N=18)$} & Pain 36\% (5/14) & $36 \%(5 / 14)$ & $29 \%(4 / 14)$ & \\
\hline & Sensory $33 \%(5 / 15)$ & $53 \%(8 / 15)$ & $13 \%(2 / 15)$ & \\
\hline & Motor 38\% (5/13) & $31 \%(4 / 13)$ & $31 \%(4 / 13)$ & \\
\hline Aghakhani [2] $(N=15)$ & Postop 0\% (0/15) & $47 \%(7 / 15)$ & $53 \%(8 / 15)$ & \\
\hline \multicolumn{5}{|l|}{ Cord transection $(N=51(5.9 \%))$} \\
\hline \multirow[t]{3}{*}{ Vernon [54] $(N=5)$} & Pain $75 \%(3 / 4)$ & $25 \%(1 / 4)$ & $0 \%(0 / 4)$ & \\
\hline & Sensory $40 \%(2 / 5)$ & $0 \%(0 / 5)$ & $60 \%(3 / 5)$ & \\
\hline & Motor $100 \%(3 / 3)$ & $0 \%(0 / 3)$ & $0 \%(0 / 3)$ & \\
\hline \multicolumn{5}{|l|}{ Syringostomy $(N=49(5.7 \%))$} \\
\hline \multirow[t]{3}{*}{ Vernon [54] $(N=22)$} & Pain 63\% (12/19) & $26 \%(5 / 19)$ & $11 \%(2 / 19)$ & \\
\hline & Sensory $31 \%(5 / 16)$ & $6 \%(1 / 16)$ & $69 \%(11 / 16)$ & \\
\hline & Motor 59\% (10/17) & $0 \%(0 / 17)$ & $41 \%(7 / 17)$ & \\
\hline \multicolumn{5}{|l|}{ Duraplasty $(N=41(4.7 \%))$} \\
\hline \multirow[t]{3}{*}{ Schaan $[42](N=12)$} & Pain $100 \%(4 / 4)$ & $0 \%(0 / 4)$ & $0 \%(0 / 4)$ & \\
\hline & Sensory $83 \%(10 / 12)$ & $8 \%(1 / 12)$ & $8 \%(1 / 12)$ & \\
\hline & Motor 45\% (5/11) & $36 \%(4 / 11)$ & $18 \%(2 / 11)$ & \\
\hline \multicolumn{5}{|l|}{$\begin{array}{l}\text { Arachnoid lysis + syringo-subarachnoid } \\
\quad \text { drain }(N=30(3.5 \%))\end{array}$} \\
\hline \multirow[t]{3}{*}{ Lee $[35](N=4)$} & Pain $25 \%(1 / 4)$ & & & \\
\hline & Sensory $67 \%(2 / 3)$ & & & Trans. neurol. deficit 75\% (3/4) \\
\hline & Motor 67\% (2/3) & & & CSF leak $25 \%(1 / 4)$ \\
\hline \multirow[t]{3}{*}{ Lee [34] $(N=9)$} & Pain $25 \%(2 / 8)$ & & & Failure $33 \%(3 / 9)$ \\
\hline & Sensory $33 \%(2 / 6)$ & & & Trans. neurol. deficit $67 \%(6 / 9)$ \\
\hline & Motor $50 \%(3 / 6)$ & & & CSF leak $11 \%(1 / 9)$ \\
\hline
\end{tabular}

Decompression $(N=5(0.58 \%))$. Ventriculo/lumbo-peritoneal shunt $(N=5(0.58 \%))$

Deter., deterioration; Neurol., neurological; CSF, cerebrospinal fluid; Trans., transient

45, 49]. Furthermore, one has to keep in mind that both, improvement as well as an arrest of deterioration, may constitute the goal of treatment.

Effect of type of surgical procedure on the outcome The type of surgical procedure was specified in almost 900 patients
(Table 4). Forty-eight percent of authors performed untethering, another $31 \%$ various techniques of drain placement, and $4 \%$ combined both procedures. Cord transection, syringostomy, or duraplasty were performed by around 5\%, and less than $1 \%$ applied decompression or shunt alone. While no surgical technique for PTS provides substantially superior 
results, any type of drain placement is associated with a failure rate of up to $20 \%[37,38,47]$. The reason for the weak recommendation of the 2010 consensus panel for spinal cord untethering with expansive duraplasty as the preferred firstline surgical technique is not obvious [7]. From a pathophysiological point of view, an individualized therapeutic approach would be desirable based on the patient's history, symptoms, and radiological findings. After the detection of local alterations in CSF flow, the restoration of physiological flow patterns should be the first goal followed by draining CSF trapped in cysts. Duraplasty may aid in the creation of extra CSF space and avoid new scar formation. Cell transplantation therapies in PTS are under investigation, although their relevance has not been confirmed yet [57, 63].

Time interval to surgical intervention Experimental evidence indicates that mechanical perturbations of arachnoiditis form the basis of syrinx development [15], and medullary edema in MRI can be interpreted as a "pre-syrinx "[20] as suggested by Lyons et al. in the pre-MRI area [40]. These pathophysiological considerations may stress the relevance of an early intervention to divert CSF if the spinal canal stenosis is not absolute $[13,29,40,53]$. Irrespectively, it is self-evident that the spinal stabilization and re-alignment of fractures preventing medullar compression and kyphosis is mandatory [2, 44, 49]. Interestingly, the 2010 consensus committee recommended against the direct decompression at the time of initial injury as well as against surgical interventions for patients developing sensory loss, a pain syndrome, or for asymptomatic but expanding syrinx [7].

Some authors do not support the use of a surgical intervention in PTS, even in patients with progressive neurological deterioration [45]. Our analysis suggests that a conservative treatment as reported by some authors $[4,5,11,14,25,33,34$, $40,45,49]$ may be an alternative to surgical procedures flawed by complications. However, because of the observational design of all studies, we cannot exclude that our analysis is biased by a crossover of patients who were initially treated conservatively and were referred to a subsequent surgical treatment because of clinical deterioration. Furthermore, it is important to keep in mind that scar formation itself without PTS may result in neurological deterioration.

\section{Conclusion}

Here, we present the analysis of a systematic literature search on therapeutic options for PTS over four decades. The outcome of conservative and surgical treatment is not directly comparable because of the exclusively observational study design with the subsequent selection bias and cross-over. While a satisfying outcome defined as either an improved or stable situation is identical (conservative $85 \%$; surgery $88 \%$ ), the reduction of deterioration from $15.5 \%$ without surgery to $9.1 \%$ with surgery is accompanied by a $0.33 \%$ surgery-related mortality and $23 \%$ complications. The evidence of the efficacy of the different treatment modalities is very low mainly resulting from the application of observational study designs with a consistently high risk of selection bias. This points to the necessity of additional research using appropriate study designs to reveal the causal relationship between treatment and outcome. However, concerning the existing literature, there is no satisfactory standard treatment for syringomyelia even diagnosing PTS early in its evolution. Hence, PTS remains a neurosurgical challenge even diagnosed early in its course.

Funding Information Open Access funding provided by Projekt DEAL.

\section{Compliance with ethical standards}

Conflict of interest The authors declare that they have no conflict of interest.

Informed consent For this type of study, formal consent is not required.

Open Access This article is licensed under a Creative Commons Attribution 4.0 International License, which permits use, sharing, adaptation, distribution and reproduction in any medium or format, as long as you give appropriate credit to the original author(s) and the source, provide a link to the Creative Commons licence, and indicate if changes were made. The images or other third party material in this article are included in the article's Creative Commons licence, unless indicated otherwise in a credit line to the material. If material is not included in the article's Creative Commons licence and your intended use is not permitted by statutory regulation or exceeds the permitted use, you will need to obtain permission directly from the copyright holder. To view a copy of this licence, visit http://creativecommons.org/licenses/by/4.0/.

\section{References}

1. Abel R, Gerner HJ, Smit C, Meiners T (1999) Residual deformity of the spinal canal in patients with traumatic paraplegia and secondary changes of the spinal cord. Spinal Cord 37:14-19

2. Aghakhani N, Baussart B, David P, Lacroix C, Benoudiba F, Tadie M, Parker F (2010) Surgical treatment of posttraumatic syringomyelia. Neurosurgery 66:1120-1127; discussion 1127 . https://doi.org/ 10.1227/01.NEU.0000369609.30695.AB

3. Alisauskaite N, Spitzbarth I, Baumgartner W, Dziallas P, Kramer S, Dening R, Stein VM, Tipold A (2017) Chronic post-traumatic intramedullary lesions in dogs, a translational model. PLoS One 12:e0187746. https://doi.org/10.1371/journal.pone.0187746

4. Anton HA, Schweigel JF (1986) Posttraumatic syringomyelia: the British Columbia experience. Spine (Phila Pa 1976) 11:865-868. https://doi.org/10.1097/00007632-198611000-00003

5. Asano M, Fujiwara K, Yonenobu K, Hiroshima K (1996) Posttraumatic syringomyelia. Spine (Phila Pa 1976) 21:1446-1453

6. Batnitzky S, Price HI, Gaughan MJ, Hall PV, Rosenthal SJ (1983) The radiology of syringohydromyelia. RadioGraphics 3:585-611. https://doi.org/10.1148/radiographics.3.4.585 
7. Bonfield CM, Levi AD, Arnold PM, Okonkwo DO (2010) Surgical management of post-traumatic syringomyelia. Spine (Phila Pa 1976) 35:S245-S258. https://doi.org/10.1097/BRS. 0b013e3181f32e9c

8. Brodbelt AR, Stoodley MA, Watling AM, Tu J, Burke S, Jones NR (2003) Altered subarachnoid space compliance and fluid flow in an animal model of posttraumatic syringomyelia. Spine (Phila $\mathrm{Pa}$ 1976) 28:E413-E419. https://doi.org/10.1097/01.BRS. 0000092346.83686.B9

9. Cacciola F, Capozza M, Perrini P, Benedetto N, Di Lorenzo N (2009) Syringopleural shunt as a rescue procedure in patients with syringomyelia refractory to restoration of cerebrospinal fluid flow. Neurosurgery 65:471-476; discussion 476. https://doi.org/10.1227/ 01.NEU.0000350871.47574.DE

10. Cao F, Yang XF, Liu WG, Li G, Zheng XS, Wen L (2007) Surgery for posttraumatic syringomyelia: a retrospective study of seven patients. Chin J Traumatol 10:366-370

11. Carroll AM, Brackenridge P (2005) Post-traumatic syringomyelia: a review of the cases presenting in a regional spinal injuries unit in the north east of England over a 5-year period. Spine (Phila Pa 1976) 30:1206-1210

12. Dodoo-Schittko F, Brandstetter S, Blecha S, Thomann-Hackner K, Brandl M, Knuttel H, Bein T, Apfelbacher C (2017) Determinants of quality of life and return to work following acute respiratory distress syndrome. Dtsch Arztebl Int 114:103-109. https://doi.org/ 10.3238/arztebl.2017.0103

13. Edgar R, Quail P (1994) Progressive post-traumatic cystic and noncystic myelopathy. Br J Neurosurg 8:7-22

14. el Masry WS, Biyani A (1996) Incidence, management, and outcome of post-traumatic syringomyelia. In memory of Mr Bernard Williams. J Neurol Neurosurg Psychiatry 60:141-146

15. Elliott NS, Lockerby DA, Brodbelt AR (2011) A lumped-parameter model of the cerebrospinal system for investigating arterial-driven flow in posttraumatic syringomyelia. Med Eng Phys 33:874-882. https://doi.org/10.1016/j.medengphy.2010.07.009

16. Ewelt C, Stalder S, Steiger HJ, Hildebrandt G, Heilbronner R (2010) Impact of cordectomy as a treatment option for posttraumatic and non-posttraumatic syringomyelia with tethered cord syndrome and myelopathy. J Neurosurg Spine 13:193-199. https:// doi.org/10.3171/2010.3.SPINE0976

17. Fairholm DJ, Turnbull IM (1971) Microangiographic study of experimental spinal cord injuries. J Neurosurg 35:277-286

18. Falci SP, Indeck C, Lammertse DP (2009) Posttraumatic spinal cord tethering and syringomyelia: surgical treatment and longterm outcome. J Neurosurg Spine 11:445-460. https://doi.org/10. 3171/2009.4.SPINE09333

19. Fehlings MG, Wilson JR, Kopjar B, Yoon ST, Arnold PM, Massicotte EM, Vaccaro AR, Brodke DS, Shaffrey CI, Smith JS, Woodard EJ, Banco RJ, Chapman JR, Janssen ME, Bono CM, Sasso RC, Dekutoski MB, Gokaslan ZL (2013) Efficacy and safety of surgical decompression in patients with cervical spondylotic myelopathy: results of the AOSpine North America prospective multi-center study. J Bone Joint Surg Am 95:1651-1658. https:// doi.org/10.2106/JBJS.L.00589

20. Fischbein NJ, Dillon WP, Cobbs C, Weinstein PR (2000) The "presyrinx" state: is there a reversible myelopathic condition that may precede syringomyelia? Neurosurg Focus 8:E4

21. Gardner WJ (1965) Hydrodynamic mechanism of syringomyelia: its relationship to myelocele. J Neurol Neurosurg Psychiatry 28: 247-259

22. Ghogawala Z, Martin B, Benzel EC, Dziura J, Magge SN, Abbed KM, Bisson EF, Shahid J, Coumans JV, Choudhri TF, Steinmetz MP, Krishnaney AA, King JT Jr, Butler WE, Barker FG 2nd, Heary RF (2011) Comparative effectiveness of ventral vs dorsal surgery for cervical spondylotic myelopathy. Neurosurgery 68:622-630; discussion 630-621. https://doi.org/10.1227/NEU. 0b013e31820777cf

23. Hayashi T, Ueta T, Kubo M, Maeda T, Shiba K (2013) Subarachnoid-subarachnoid bypass: a new surgical technique for posttraumatic syringomyelia. J Neurosurg Spine 18:382-387. https://doi.org/10.3171/2013.1.SPINE12828

24. Hess MJ, Foo D (2001) Shunting for syringomyelia in patients with spinal cord injuries: self-reported, long-term effects in 8 patients. Arch Phys Med Rehabil 82:1633-1636. https://doi.org/10.1053/ apmr.2001.25075

25. Hida K, Iwasaki Y, Imamura H, Abe H (1994) Posttraumatic syringomyelia: its characteristic magnetic resonance imaging findings and surgical management. Neurosurgery 35:886-891 discussion 891

26. Holly LT, Johnson JP, Masciopinto JE, Batzdorf U (2000) Treatment of posttraumatic syringomyelia with extradural decompressive surgery. Neurosurg Focus 8:E8

27. Holmstrom U, Tsitsopoulos PP, Flygt H, Holtz A, Marklund N (2018) Neurosurgical untethering with or without syrinx drainage results in high patient satisfaction and favorable clinical outcome in post-traumatic myelopathy patients. Spinal Cord 56:873-882. https://doi.org/10.1038/s41393-018-0094-y

28. Isik N, Elmaci I, Isik N, Cerci SA, Basaran R, Gura M, Kalelioglu $M$ (2013) Long-term results and complications of the syringopleural shunting for treatment of syringomyelia: a clinical study. Br J Neurosurg 27:91-99. https://doi.org/10.3109/ 02688697.2012.703350

29. Jaksche H, Schaan M, Schulz J, Bosczcyk B (2005) Posttraumatic syringomyelia-a serious complication in tetra- and paraplegic patients. Acta Neurochir Suppl 93:165-167

30. Karam Y, Hitchon PW, Mhanna NE, He W, Noeller J (2014) Posttraumatic syringomyelia: outcome predictors. Clin Neurol Neurosurg 124:44-50. https://doi.org/10.1016/j.clineuro.2014.06. 007

31. Kim HG, Oh HS, Kim TW, Park KH (2014) Clinical features of post-traumatic Syringomyelia. Korean J Neurotrauma 10:66-69. https://doi.org/10.13004/kjnt.2014.10.2.66

32. Klekamp J (2012) Treatment of posttraumatic syringomyelia. J Neurosurg Spine 17:199-211. https://doi.org/10.3171/2012.5. SPINE11904

33. Kramer KM, Levine AM (1997) Posttraumatic syringomyelia: a review of 21 cases. Clin Orthop Relat Res:190-199

34. La Haye PA, Batzdorf U (1988) Posttraumatic syringomyelia. West J Med 148:657-663

35. Lam S, Batzdorf U, Bergsneider M (2008) Thecal shunt placement for treatment of obstructive primary syringomyelia. J Neurosurg Spine 9:581-588. https://doi.org/10.3171/SPI.2008.10.08638

36. Laxton AW, Perrin RG (2006) Cordectomy for the treatment of posttraumatic syringomyelia. Report of four cases and review of the literature. J Neurosurg Spine 4:174-178. https://doi.org/10. 3171/spi.2006.4.2.174

37. Lee TT, Alameda GJ, Gromelski EB, Green BA (2000) Outcome after surgical treatment of progressive posttraumatic cystic myelopathy. J Neurosurg 92:149-154

38. Lee TT, Alameda GJ, Camilo E, Green BA (2001) Surgical treatment of post-traumatic myelopathy associated with syringomyelia. Spine (Phila Pa 1976) 26:S119-S127

39. Lee JH, Chung CK, Kim HJ (2002) Decompression of the spinal subarachnoid space as a solution for syringomyelia without Chiari malformation. Spinal Cord 40:501-506. https://doi.org/10.1038/sj. sc. 3101322

40. Lyons BM, Brown DJ, Calvert JM, Woodward JM, Wriedt $\mathrm{CH}$ (1987) The diagnosis and management of post traumatic syringomyelia. Paraplegia 25:340-350. https://doi.org/10.1038/sc.1987.62 
41. Milhorat TH, Johnson RW, Milhorat RH, Capocelli AL Jr, Pevsner PH (1995) Clinicopathological correlations in syringomyelia using axial magnetic resonance imaging. Neurosurgery 37:206-213

42. Oluigbo CO, Thacker K, Flint G (2010) The role of lumboperitoneal shunts in the treatment of syringomyelia. J Neurosurg Spine 13:133-138. https://doi.org/10.3171/2010.3. SPINE0964

43. Padovani R, Cavallo M, Gaist G (1989) Surgical treatment of syringomyelia: favorable results with syringosubarachnoid shunting. Surg Neurol 32:173-180

44. Perrouin-Verbe B, Robert R, Lefort M, Agakhani N, Tadie M, Mathe JF (1999) Post-traumatic syringomyelia. Neurochirurgie 45(Suppl 1):58-66

45. Ronen J, Catz A, Spasser R, Gepstein R (1999) The treatment dilemma in post-traumatic syringomyelia. Disabil Rehabil 21: 455-457

46. Rossier AB, Foo D, Shillito J, Dyro FM (1985) Posttraumatic cervical syringomyelia. Incidence, clinical presentation, electrophysiological studies, syrinx protein and results of conservative and operative treatment. Brain 108(Pt 2):439-461. https://doi.org/10. 1093/brain/108.2.439

47. Schaan M, Jaksche H (2001) Comparison of different operative modalities in post-traumatic syringomyelia: preliminary report. Eur Spine J 10:135-140. https://doi.org/10.1007/s005860000197

48. Schaller B, Mindermann T, Gratzl O (1999) Treatment of syringomyelia after posttraumatic paraparesis or tetraparesis. J Spinal Disord 12:485-488

49. Schurch B, Wichmann W, Rossier AB (1996) Post-traumatic syringomyelia (cystic myelopathy): a prospective study of 449 patients with spinal cord injury. J Neurol Neurosurg Psychiatry 60:61-67

50. Sgouros S, Williams B (1995) A critical appraisal of drainage in syringomyelia. J Neurosurg 82:1-10. https://doi.org/10.3171/jns. 1995.82.1.0001

51. Shannon N, Symon L, Logue V, Cull D, Kang J, Kendall B (1981) Clinical features, investigation and treatment of post-traumatic syringomyelia. J Neurol Neurosurg Psychiatry 44:35-42

52. Suzuki M, Davis C, Symon L, Gentili F (1985) Syringoperitoneal shunt for treatment of cord cavitation. J Neurol Neurosurg Psychiatry 48:620-627
53. Tator CH, Briceno C (1988) Treatment of syringomyelia with a syringosubarachnoid shunt. Can J Neurol Sci 15:48-57

54. Tator CH, Meguro K, Rowed DW (1982) Favorable results with syringosubarachnoid shunts for treatment of syringomyelia. J Neurosurg 56:517-523. https://doi.org/10.3171/jns.1982.56.4. 0517

55. Ushewokunze SO, Gan YC, Phillips K, Thacker K, Flint G (2010) Surgical treatment of post-traumatic syringomyelia. Spinal Cord 48:710-713. https://doi.org/10.1038/sc.2010.17

56. Vaquero J, Martinez R, Salazar J, Santos H (1987) Syringosubarachnoid shunt for treatment of syringomyelia. Acta Neurochir 84:105-109

57. Vaquero J, Hassan R, Fernandez C, Rodriguez-Boto G, Zurita M (2017) Cell therapy as a new approach to the treatment of posttraumatic syringomyelia. World Neurosurg 107:1047 e1045-1047 e1048. https://doi.org/10.1016/j.wneu.2017.08.019

58. Vernon JD, Silver JR, Ohry A (1982) Post-traumatic syringomyelia. Paraplegia 20:339-364. https://doi.org/10.1038/sc.1982.64

59. Vernon JD, Silver JR, Symon L (1983) Post-traumatic syringomyelia: the results of surgery. Paraplegia 21:37-46. https://doi.org/10. 1038/sc. 1983.6

60. Wiart L, Dautheribes M, Pointillart V, Gaujard E, Petit H, Barat M (1995) Mean term follow-up of a series of post-traumatic syringomyelia patients after syringo-peritoneal shunting. Paraplegia 33: 241-245. https://doi.org/10.1038/sc.1995.55

61. Williams B (1970) Syringomyelia. Br Med J 1:434

62. Williams B, Page N (1987) Surgical treatment of syringomyelia with syringopleural shunting. Br J Neurosurg 1:63-80

63. Wirth ED 3rd, Reier PJ, Fessler RG, Thompson FJ, Uthman B, Behrman A, Beard J, Vierck CJ, Anderson DK (2001) Feasibility and safety of neural tissue transplantation in patients with syringomyelia. J Neurotrauma 18:911-929. https://doi.org/10.1089/ 089771501750451839

Publisher's note Springer Nature remains neutral with regard to jurisdictional claims in published maps and institutional affiliations. 